Published in final edited form as:

Cancer Chemother Pharmacol. 2011 December ; 68(6): 1439-1447. doi:10.1007/s00280-011-1637-5.

\title{
Dose-Escalating and Pharmacological Study of Bortezomib in Adult Cancer Patients With Impaired Renal Function: A National Cancer Institute Organ Dysfunction Working Group Study
}

\author{
Ticiana B. Leal ${ }^{1}$, Scot C. Remick ${ }^{2}$, Chris H. Takimoto ${ }^{3}$, Ramesh K. Ramanathan ${ }^{4}$, Angela \\ Davies $^{5}$, Merrill J. Egorin ${ }^{4}$, Anne Hamilton ${ }^{6}$, Patricia A. LoRusso ${ }^{7}$, Stephen Shibata ${ }^{8}$, Heinz- \\ Josef Lenz ${ }^{9}$, James Mier ${ }^{10}$, John Sarantopoulos ${ }^{3}$, Sridhar Mani ${ }^{11}$, John J. Wright ${ }^{12}, \mathbf{S}$. \\ Percy Ivy ${ }^{12}$, Rachel Neuwirth ${ }^{13}$, Lisa von Moltke ${ }^{13}$, Karthik Venkatakrishnan ${ }^{13}$, and Daniel \\ Mulkerin ${ }^{1}$ \\ ${ }^{1}$ University of Wisconsin Carbone Cancer Center, Madison, WI \\ ${ }^{2}$ Comprehensive Cancer Center at University Hospitals of Cleveland and Case Western Reserve \\ University, Cleveland, $\mathrm{OH}$ \\ ${ }^{3}$ Institute for Drug Development, Cancer Therapy and Research Center, University of Texas \\ Health Science Center, San Antonio, TX \\ ${ }^{4}$ University of Pittsburgh Cancer Institute, Pittsburgh, PA \\ ${ }^{5}$ UC Davis Cancer Center, Sacramento, CA \\ ${ }^{6}$ Sydney Cancer Centre, Sydney, Australia \\ ${ }^{7}$ Wayne State University, Detroit, MI \\ ${ }^{8}$ City of Hope National Medical Center, Duarte, CA \\ 9USC/Norris Comprehensive Cancer Center, Los Angeles, CA \\ ${ }^{10}$ Beth Israel Deaconess Medical Center Boston, MA \\ ${ }^{11}$ Montefiore Hospital, Albert Einstein College of Medicine, Bronx, NY \\ ${ }^{12}$ Investigational Drug Branch, Cancer Therapy Evaluation Program, Division of Cancer \\ Treatment and Diagnosis, National Cancer Institute, Bethesda, MD \\ ${ }^{13}$ Millennium Pharmaceuticals, Inc., Cambridge, MA
}

\begin{abstract}
Purpose-To determine the toxicities, pharmacokinetics, pharmacodynamics, and maximum tolerated dose of bortezomib in patients with renal impairment, and to develop dosing guidelines for such a patient population.
\end{abstract}

\footnotetext{
Corresponding author and address for reprints: Daniel Mulkerin, MD, University of Wisconsin Carbone Cancer Center, 600 Highland Ave, Madison, WI, 53792, Tel: (608) 262-9653, Fax: (608) 263-8613, dm2@medicine.wisc.edu.

Prior presentations of the study:

Mulkerin D, Remick S, Ramanathan R, et al. A dose-escalating and pharmacologic study of bortezomib in adult cancer patients with impaired renal function. JCO 2006;24:abstract 2032. Poster presentation at 2006 ASCO Annual Meeting.

Mulkerin D, Remick S, Takimoto C, et al. Safety, tolerability, and pharmacology of bortezomib in cancer patients with impaired renal function, including patients requiring dialysis: results from a prospective phase 1 study. Blood 2007;110:abstract 3477. Poster presentation at 2007 ASH Annual Meeting.
} 
Patients and Methods-Sixty-two adult cancer patients received intravenous bortezomib at $0.7-1.5 \mathrm{mg} / \mathrm{m}^{2}$ on days $1,4,8$, and 11 every 3 weeks. Patients were stratified by 24 -hour creatinine clearance $(\mathrm{CrCl})$ normalized to body surface area (BSA) $1.73 \mathrm{~m}^{2}$ into five cohorts: normal renal function ( $\left.₫ 0 \mathrm{~mL} / \mathrm{min} / 1.73 \mathrm{~m}^{2}\right)$; mild dysfunction $\left(40-59 \mathrm{~mL} / \mathrm{min} / 1.73 \mathrm{~m}^{2}\right)$; moderate dysfunction $\left(20-39 \mathrm{~mL} / \mathrm{min} / 1.73 \mathrm{~m}^{2}\right)$; severe dysfunction $\left(<20 \mathrm{~mL} / \mathrm{min} / 1.73 \mathrm{~m}^{2}\right)$; and dialysis. Dose escalation was planned for the four cohorts with renal dysfunction. Plasma bortezomib concentrations and blood 20S proteasome inhibition were assayed.

Results-Bortezomib escalation to the standard $1.3 \mathrm{mg} / \mathrm{m}^{2}$ dose was well tolerated in all patients with $\mathrm{CrCl} \geq 20 \mathrm{~mL} / \mathrm{min} / 1.73 \mathrm{~m}^{2} ; 0.7 \mathrm{mg} / \mathrm{m}^{2}$ was tolerated in three patients with severe renal dysfunction $\left(<20 \mathrm{~mL} / \mathrm{min} / 1.73 \mathrm{~m}^{2}\right)$. Bortezomib dose escalation was well tolerated in nine dialysis patients, including to $1.3 \mathrm{mg} / \mathrm{m}^{2}$ in four patients. Decreased $\mathrm{CrCl}$ did not affect bortezomib pharmacokinetics or pharmacodynamics. Bortezomib-related side-effects were neither more common nor severe in patients with renal dysfunction versus those with normal renal function.

Conclusion-Bortezomib $1.3 \mathrm{mg} / \mathrm{m}^{2}$ is well tolerated, and dose reductions are not necessary in patients with renal dysfunction. Extrapolation from clinical and pharmacologic data suggests patients with severe renal dysfunction, including dialysis patients, can receive bortezomib at the full dose established to be clinically effective in the general patient population.

\section{INTRODUCTION}

The ubiquitin-proteasome pathway has an essential role in the breakdown of many intracellular proteins[1-3]. Following ubiquitination, proteins, including those involved in cell-cycle regulation[4], angiogenesis[5], apoptosis[6], and cell adhesion[7, 8] are lysed by the proteasome. Due to the many processes affected by the proteasome, proteasome inhibition results in a wide range of cellular effects $[9,10]$.

Bortezomib is a highly selective and reversible proteasome inhibitor that is approved for treatment of patients with multiple myeloma (MM) or mantle cell lymphoma (MCL) who have received at least one prior therapy. Bortezomib activity in MM and MCL patients is clear, with overall response rates of $43 \%$, including $9 \%$ complete response (CR), in relapsed/refractory MM patients[11], 71\%, including 30\% CR, in newly diagnosed MM patients (when administered with melphalan-prednisone)[12], and 32\%, including $8 \% \mathrm{CR}$, in relapsed/refractory MCL patients[13]. Bortezomib is well tolerated by MM and MCL patients; major side-effects include peripheral neuropathy, myelosuppression, and hypotension.

Although MM patients with significant renal impairment have been included in previous clinical trials of bortezomib[14,15], no study has prospectively evaluated the safety of bortezomib in patients with renal impairment. A full pharmacokinetic and pharmacodynamic evaluation was indicated, to allow the development of dosing guidelines for the use of bortezomib in these patients. The primary objectives of the present study by the Organ Dysfunction Working Group (ODWG) of the National Cancer Institute Cancer Treatment Evaluation Program (NCI CTEP) were to evaluate the safety, tolerability, and maximum tolerated dose and to characterize the pharmacokinetic and pharmacodynamic profiles of bortezomib in adults with advanced malignancies and renal dysfunction.

\section{PATIENT AND METHODS}

\section{Patient Eligibility}

Enrollment was limited to patients with histologically confirmed advanced malignancy, including non-Hodgkin's lymphoma and MM, for whom effective standard therapy was not available. Inclusion criteria were: measurable or evaluable disease; Eastern Cooperative 
Oncology Group (ECOG) performance status 0-2; life expectancy $\geq 12$ weeks; age $\geq 18$ years; absolute neutrophil count $\geq 1000 / \mu \mathrm{l}$, platelets $250,000 / \mu \mathrm{l}$; total bilirubin $\leq .5 \mathrm{X}$ upper limit of normal [ULN], aspartate aminotransferase $\_.5 \times$ ULN, or $5 \times$ ULN in cases of liver involvement. Exclusion criteria included peripheral neuropathy zgrade 2 (NCI Common Toxicity Criteria version 2.0 [CTC v2.0]), chemotherapy or radiation therapy within the previous 4 weeks, prior radiation to $>50 \%$ of bone marrow, symptomatic central nervous system metastases, serious or uncontrolled concurrent medical illness, and highly active antiretroviral therapy. There was no limit on previous chemotherapy, excepting no previous bortezomib. All patients gave informed consent according to institutional guidelines.

\section{Study Design}

Eleven institutions enrolled patients to one of five cohorts according to measured $\mathrm{CrCl}$ normalized to body surface area (BSA) of $1.73 \mathrm{~m}^{2}$. BSA normalization was employed to avoid penalizing smaller patients by placing them in poorer renal function groups. The cohorts were: normal renal function, $\mathrm{CrCl} \succeq 60 \mathrm{~mL} / \mathrm{min} / 1.73 \mathrm{~m}^{2}$; mild dysfunction, $\mathrm{CrCl} 40$ $59 \mathrm{~mL} / \mathrm{min} / 1.73 \mathrm{~m}^{2}$; moderate dysfunction, $\mathrm{CrCl} 20-39 \mathrm{~mL} / \mathrm{min} / 1.73 \mathrm{~m}^{2}$; severe dysfunction, $\mathrm{CrCl}<20 \mathrm{~mL} / \mathrm{min} / 1.73 \mathrm{~m}^{2}$; and dialysis. Two separate 24-hour urinary $\mathrm{CrCl}$ determinations that did not deviate by more than $25 \%$ were required, with the most recent being performed within 1 week before treatment. Cohort assignment was based on the most recent $\mathrm{CrCl}$ measurement. No minimum volume of urine within a 24-hour period was required. Laboratories at each participating institution were used for creatinine assessments, and no cross-site standardization or corrections among laboratory assay methods was performed.

Bortezomib (VELCADE ${ }^{\circledR}$, Millennium Pharmaceuticals, Inc, and Johnson \& Johnson Pharmaceutical Research \& Development LLC) was provided to the NCI under a CRADA with Millennium Pharmaceuticals. Bortezomib was reconstituted with $3.5 \mathrm{~mL}$ normal saline USP and administered as an intravenous push over 30 seconds on days $1,4,8$, and 11 every three weeks at $0.7 \mathrm{mg} / \mathrm{m}^{2}, 1.0 \mathrm{mg} / \mathrm{m}^{2}, 1.3 \mathrm{mg} / \mathrm{m}^{2}$ or $1.5 \mathrm{mg} / \mathrm{m}^{2}$. Bortezomib was administered to dialysis patients after dialysis. Three patients were enrolled per dose level per renal function group and monitored for cycle 1 dose-limiting toxicities (DLTs). A DLT was defined as one of the following considered probably or definitely related to bortezomib: grade 4 neutropenia for $\geq 7$ days, neutropenic fever, grade 4 thrombocytopenia for $\geq 7$ days, grade 4 anemia for $\geq 7$ days; grade $\geq 3$ nausea and vomiting despite maximal anti-emetic treatment, grade $\geq 3$ diarrhea despite maximal anti-diarrheal therapy, any other grade $\geq 3$ nonhematologic toxicity; and renal toxicity, defined as increased creatinine or decreased $\mathrm{CrCl}$ that reclassified a patient into a poorer renal function group.

If no cycle 1 DLTs were observed, the dose was escalated for the next three-patient cohort in the same renal function group. If one of the first three patients experienced a DLT, the cohort was expanded up to six. If $\geq 2$ patients experienced a DLT at any dose level, dose escalation was terminated, and additional patients were enrolled at the next lowest dose level. A minimum of six patients were to be treated at the highest tolerated dose level in each renal function group. The normal renal function group included 15 patients treated at full dose as pharmacokinetic controls. At the time of study design, bortezomib $1.5 \mathrm{mg} / \mathrm{m}^{2}$ was considered an appropriate full dose, but as further data became available, the full dose was designated as $1.3 \mathrm{mg} / \mathrm{m}^{2}$. All patients received full supportive care. By study design the mild renal dysfunction group began dosing at $1.0 \mathrm{mg} / \mathrm{m}^{2}$, while the moderate, severe and dialysis groups began at $0.7 \mathrm{mg} / \mathrm{m}^{2}$. If dose escalation was halted in the mild or moderate dysfunction groups, further escalation above this dose level was not permitted in the more severe dysfunction groups. During the trial, the $1.3 \mathrm{mg} / \mathrm{m}^{2}$ cohorts in the mild and moderate 
groups were each expanded to 12 patients to characterize more fully pharmacokinetic and pharmacodynamic parameters.

Laboratory tests were performed weekly, and response was evaluated using RECIST criteria[16] for solid tumors and appropriate criteria for hematologic malignancies[17-20].

\section{Pharmacokinetic and pharmacodynamic analyses}

Blood samples for pharmacokinetics were obtained on days 1 and 8 of cycle 1, before treatment and 5, 15, 30, and 60 minutes, and 2, 4, 6, 8, 12, and 24 hours after bortezomib dosing. At each time, $5 \mathrm{~mL}$ of venous blood was drawn into an EDTA-containing tube and mixed gently. Samples were centrifuged immediately at $1200 \times g$ for 15 minutes in a refrigerated centrifuge to prepare plasma, which was frozen immediately at $-70^{\circ} \mathrm{C}$ or colder. Bortezomib concentrations in plasma were determined using a selective, accurate, and reproducible liquid chromatography/tandem mass spectrometry (LC/MS/MS) assay performed at Advion BioSciences, Inc, (Ithaca, New York). Following addition of $\left[{ }^{13} \mathrm{C}_{9}\right]$ bortezomib internal standard, plasma samples $(0.15 \mathrm{~mL})$ were subject to protein precipitation with $600 \mu \mathrm{L}$ of cold $0.1 \%$ formic acid in acetonitrile, vortex mixed and centrifuged. Supernatants were evaporated to dryness at $35^{\circ} \mathrm{C}$ and reconstituted in $100 \mu \mathrm{L}$ of acetonitrile:water $(10: 90, \mathrm{v} / \mathrm{v})$. Chromatography was performed using a Luna $\mathrm{C}_{18}(2)$ column $(3 \mu \mathrm{m}, 2.1 \mathrm{~mm} \times 30 \mathrm{~mm})$ (Phenomenex, Inc., Torrance, CA) and a $0.1 \%$ ammonium formate/acetonitrile gradient mobile phase (flow rate $0.2 \mathrm{~mL} / \mathrm{min}$ ). Mass spectrometric detection was performed with a SCIEX API 3000 mass spectrometer (Applied Biosystems, Concord, Ontario), using selected reaction monitoring in the negative ion mode $(\mathrm{m} / \mathrm{Z}$ transitions $383.2 \rightarrow 322.2$ for bortezomib; $392.2 \rightarrow 331.2$ for internal standard). The assay demonstrated a lower limit of quantitation of $0.5 \mathrm{ng} / \mathrm{mL}$ for bortezomib. The calibration curve was linear from $0.5 \mathrm{ng} / \mathrm{mL}$ to $30 \mathrm{ng} / \mathrm{mL}$. The coefficient of determination $\left(\mathrm{r}^{2}\right)$ of the calibration curve was 0.9955 . The inter-assay precision $(\mathrm{CV})$ of the analytical quality control samples ranged from $7.0 \%$ to $10.9 \%$. The mean accuracy (\% deviation) ranged from $7.3 \%$ to $-4.8 \%$.

Pharmacodynamic analysis involved assessment of 20S proteasome inhibition; 5-mL venous blood samples were collected on days 1 and 8 of cycle 1 prior to and 1, 6, and 24 hours following completion of the bortezomib infusion. $20 \mathrm{~S}$ proteasome activity was measured at Millennium Pharmaceuticals using a previously described assay based on proteasomal chymotryptic and tryptic activities [21].

\section{Data analysis}

Individual plasma concentration versus time data were analyzed by noncompartmental methods using WinNonlin ${ }^{\mathrm{TM}}$ Version 5 to estimate bortezomib pharmacokinetic parameters on days 1 and 8 . The primary pharmacokinetic endpoints for comparison between renal function groups were BSA-normalized plasma clearance of bortezomib $\left(\mathrm{L} / \mathrm{h} / \mathrm{m}^{2}\right)$ and total body plasma clearance of bortezomib $(\mathrm{L} / \mathrm{h})$. Dose-normalized $\mathrm{C}_{\max }$ and half-life were also calculated. Bortezomib clearance was descriptively summarized by renal function group, and linear regression analyses were performed to explore potential associations to BSAnormalized creatinine clearance. Percentage inhibition of blood 20S proteasome activity was summarized and graphically presented over time, by dose group and renal function category.

\section{RESULTS}

\section{Patient Demographics (Table 1)}

Sixty-two patients were enrolled between April 2003 and December 2006 (Table 1). The University of Wisconsin Carbone Comprehensive Cancer Center was the coordinating site. 
Targeted patient accrual goals were met in each renal dysfunction group except the severe dysfunction and dialysis groups. Fifteen patients were enrolled to the normal renal function group $\left(\mathrm{CrCl} \ 60 \mathrm{~mL} / \mathrm{min} / 1.73 \mathrm{~m}^{2}\right), 17$ to the mild dysfunction group $(\mathrm{CrCl} 40-59 \mathrm{~mL} / \mathrm{min} /$ $\left.1.73 \mathrm{~m}^{2}\right), 18$ to the moderate dysfunction group $\left(\mathrm{CrCl} 20-39 \mathrm{~mL} / \mathrm{min} / 1.73 \mathrm{~m}^{2}\right), 3$ to the severe dysfunction group $\left(\mathrm{CrCl}<20 \mathrm{~mL} / \mathrm{min} / 1.73 \mathrm{~m}^{2}\right)$, and 9 to the dialysis group.

\section{Bortezomib Exposure and Clinical Toxicities}

A total of 263 cycles of bortezomib were administered (Table 2). Eight patients received $>6$ cycles of therapy. Toxicities were mild overall. There were no severe drug-related toxicities, and myelosuppression was modest (Table 3). The main non-hematologic toxicities included nausea, vomiting, diarrhea, fatigue and peripheral neuropathy (Table 3). Only one DLT was reported; a grade 3 hypotensive event in cycle 1 in the moderate dysfunction group. There were no grade 4 toxicities.

The 15 patients with normal renal function received a total of 99 cycles of bortezomib (Table 2). One patient received one cycle of bortezomib $1.5 \mathrm{mg} / \mathrm{m}^{2}$; the remainder received bortezomib $1.3 \mathrm{mg} / \mathrm{m}^{2}$. Grade 3 toxicities included neutropenia, lymphopenia, diarrhea (improved with maximal anti-diarrheal therapy) and fatigue (Table 3).

In the mild dysfunction group, 3 patients received a total of 8 cycles of bortezomib $1 \mathrm{mg} / \mathrm{m}^{2}$, and 14 patients received a total of 32 cycles of $1.3 \mathrm{mg} / \mathrm{m}^{2}$ (Table 2). Both dose levels were well tolerated. (Table 3). Myelosuppression was modest and included infrequent grade 3 lymphopenia, grade 3 thrombocytopenia, and grade 3 neutropenia (Table 3). Grade 3 nonhematologic toxicities included nausea and fatigue (Table 3).

In the moderate dysfunction group, 4 patients received a total of 20 cycles of bortezomib 0.7 $\mathrm{mg} / \mathrm{m}^{2}, 3$ received a total of 30 cycles of $1 \mathrm{mg} / \mathrm{m}^{2}$, and 11 received a total of 39 cycles of $1.3 \mathrm{mg} / \mathrm{m}^{2}$ (Table 2). One patient had a grade 3 hypotensive event in the first cycle, which was considered a DLT. Other grade 3 toxicities included lymphopenia, thrombocytopenia, anemia, and fatigue (Table 3).

Only three patients were enrolled to the severe dysfunction group, and they received a total of 4 cycles of bortezomib $0.7 \mathrm{mg} / \mathrm{m}^{2}$ (Table 2). All cycles were well tolerated. Grade 3 toxicity consisted of one case of lymphopenia (Table 3).

In the dialysis group, 3 patients received a total of 6 cycles of bortezomib $0.7 \mathrm{mg} / \mathrm{m}^{2}, 2$ received a total of 6 cycles of $1 \mathrm{mg} / \mathrm{m}^{2}$, and 4 received a total of 19 cycles of $1.3 \mathrm{mg} / \mathrm{m}^{2}$ (Table 2). Overall, treatment was well tolerated. Grade 3 toxicities included lymphopenia, anemia, thrombocytopenia, vomiting, diarrhea, and fatigue (Table 3).

\section{Efficacy Evaluation}

Fifty-seven of the 62 patients were evaluable for response. Five patients were not evaluable due to discontinuation per patient wishes prior to disease evaluation. One MM patient in the normal group had a partial response and remained on study for 16 months. Of the 28 patients with stable disease as best response; 8 had MM ( 3 received $>6$ cycles), 7 had renal carcinoma ( 2 received $>6$ cycles), 5 had prostate adenocarcinoma ( 1 received $>6$ cycles), and the remaining 8 had a variety of solid tumors.

\section{Pharmacokinetics}

Of the 62 enrolled patients, 56 who received bortezomib on days 1,4 , and 8 of cycle 1 without dose reductions or interruptions and had adequate bortezomib plasma concentration versus time data for pharmacokinetic analysis were included in the pharmacokinetic- 
evaluable population. Across all five renal function groups and dose levels, bortezomib displayed multiexponential disposition kinetics on days 1 and 8 , with a rapid initial distribution phase characterized by a steep decline in plasma concentrations $(>10$-fold decrease, on average, over the first hour post-dose) followed by a slower decline in plasma concentrations in the terminal phase. Visual inspection of median plasma concentration versus time plots indicated similar pharmacokinetic profiles across the renal function groups (Figure 1). Consistent with the similar pharmacokinetic profiles, mean plasma clearance values of bortezomib (expressed either as total body clearance or as BSA-normalized clearance) were similar across the renal function groups (Table 4). Across the renal function groups, mean bortezomib clearance on day 1 was 2.3-2.9-fold higher than the corresponding values on day 8 , an observation that is consistent with the previously characterized clinical pharmacokinetics of bortezomib following repeated administration[22]. A broad range of overlapping bortezomib clearance values were found in all renal function groups. The distributions of bortezomib clearance were similar and overlapping across the five renal function groups including dialysis patients (Figure 2a/2c). Scatter plots of BSA-normalized bortezomib clearance versus BSA-normalized creatinine clearance as a continuous variable and the associated regression lines and 95\% confidence bands (Figure 2b/2d) did not reveal relationships between creatinine clearance and bortezomib clearance on days 1 or 8 over the approximately 13 -fold range of BSA-normalized $\mathrm{CrCl}\left(\sim 10\right.$ to $\left.\sim 130 \mathrm{~mL} / \mathrm{min} / 1.73 \mathrm{~m}^{2}\right)$ in the study population, supporting the conclusion that $\mathrm{CrCl}$ was not predictive of bortezomib clearance. In addition, when considered in the context of inter-patient variability, renal impairment had no readily apparent effects on bortezomib dose-normalized $\mathrm{C}_{\max }$ or half-life (Table 4). However, estimates of bortezomib half-life in this study should be considered as approximate estimates because the 24-hour duration of pharmacokinetic sampling may not have been sufficient to capture the true terminal phase half-life of bortezomib[22, 23].

\section{Pharmacodynamics}

Whole blood samples from all 62 patients were assayed for $20 \mathrm{~S}$ proteasome inhibition within red blood cells. Pharmacodynamic profiles on days 1 and 8 at the $1.3 \mathrm{mg} / \mathrm{m}^{2}$ dose are shown in Supplementary Figure 1 by renal function group. Consistent with the pharmacokinetic observations, renal dysfunction had no readily apparent effect on $20 \mathrm{~S}$ proteasome inhibition.

\section{DISCUSSION}

This comprehensive evaluation of bortezomib in cancer patients with renal dysfunction demonstrates that single-agent bortezomib $1.3 \mathrm{mg} / \mathrm{m}^{2}$ administered on days $1,4,8$, and 11 every 3 weeks is well tolerated in patients with $\mathrm{CrCl} \geq 20 \mathrm{~mL} / \mathrm{min} / 1.73 \mathrm{~m}^{2}$, as well as dialysis patients. Extrapolation from the clinical and pharmacologic data suggests that therapy at doses established to be clinically effective in the general population can be given to patients with severe renal dysfunction $\left(<20 \mathrm{~mL} / \mathrm{min} / 1.73 \mathrm{~m}^{2}\right)$, including dialysis patients. In all renal dysfunction groups, the safety profile was similar to that in patients with normal renal function. Toxicities were generally mild, and no unexpected toxicities were seen, even in dialysis patients. These results confirm observations from previous retrospective studies and subanalyses of phase 3 trials of bortezomib in patients with $\mathrm{MM}[14,15,24,25]$.

The pharmacokinetics of bortezomib were not influenced by degree of renal dysfunction. As bortezomib clearance was similar across all renal function groups. The bortezomib clearance values observed in this study are similar to those seen in studies of bortezomib in patients with normal renal function[22, 23]. The decrease in clearance from day 1 to day 8 , and the variability in bortezomib clearance among patients are also consistent with results of other studies[22, 23]. Considering that clearance is the primary pharmacokinetic parameter governing the relationship between dosing and drug exposure, these results support the 
conclusion that bortezomib dose modifications are not required for patients with renal dysfunction, including dialysis patients. These results are consistent with the known elimination mechanism of bortezomib, which primarily involves hepatic metabolism[26].Additionally, the pharmacodynamic profiles, as measured by $20 \mathrm{~S}$ proteasome inhibition, were comparable across the renal function groups.. Thus, knowledge of a patient's renal function would not aid in dose individualization. These data support the clinica data indicating that bortezomib dose modification is not required for patients with renal dysfunction.

One potential limitation of the study was the lack of standardization of methods used for creatinine measurement at different participating sites. Leger and colleagues demonstrated that uncorrected use of the older Jaffe colorimetric assay for serum creatinine instead of the biochemical creatinine amidohydrolase enzymatic assay results in underestimation of $\mathrm{CrCl}$, potentially leading to underdosing of carboplatin[27]. Given the lack of association between bortezomib distribution and clearance and renal function in this study, this limitation is probably not relevant.

The planned accrual was not reached for the severe renal dysfunction group, as it was difficult to enroll patients with this level of renal dysfunction and not already on dialysis. This raises a practical question of whether the arbitrary grouping of renal impairment in our study precluded determining the MTD in this cohort, and whether a broader definition of severe renal impairment should be adopted in future studies. This multicenter trial highlights how close collaboration among industry, academia, and the federal government can address important clinical questions for the benefit of cancer patients.

In conclusion, bortezomib is a viable treatment option regardless of degree of renal dysfunction, including dialysis. Based on the findings of this study and other retrospective data, the FDA approved updated prescribing information for bortezomib, stating that dosing adjustments are not necessary for patients with renal insufficiency.

\section{Supplementary Material}

Refer to Web version on PubMed Central for supplementary material.

\section{Acknowledgments}

The authors would like to thank the nurses and research specialists of the University of Wisconsin Carbone Cancer Center Phase I Program, and acknowledge the editorial assistance of Jane Saunders of FireKite during development of this publication.

\section{Acknowledgments of research support:}

This study was supported in part by the University of Wisconsin Carbone Cancer Center UO1 CA062491 Early Clinical Trials of Anti-Cancer Agents Phase 1 grant and the Clinical and Translational Science Award 1UL1RR025011 from the National Center for Research Resources, NIH; Case Western Reserve University U01 CA62502; University of Pittsburgh Cancer Institute and Medical Center grants UO1-CA099168, UO1-CA69855, P30CA47904 and NIH/GCR \#5M01 RR 00056; City of Hope National Medical Center General Clinical Research Center grant (M01 RRR00043); University of Texas Health Science Center grant UO1-CA 069853-14; USC/Norris Comprehensive Cancer Center grant UO1-CA 62505.

\section{REFERENCES}

1. Goldberg AL, Akopian TN, Kisselev AF, Lee DH, Rohrwild M. New insights into the mechanisms and importance of the proteasome in intracellular protein degradation. Biol Chem. 1997; 378:131140. [PubMed: 9165063] 
2. Zwickl P, Baumeister W, Steven A. Dis-assembly lines: The proteosome and related ATPaseassisted proteases. Curr Opin Struct Bio. 2000; 10:242-250. [PubMed: 10753810]

3. Ciechanover A, Orian A, Schwartz AL. Ubiquitin-mediated proteolysis: Biological regulation via destruction. Bioessays. 2000; 22:442-451. [PubMed: 10797484]

4. Hershko A. Roles of ubiquitin -mediated proteolysis in cell cycle control. Curr Opin Struct Bio. 1997; 9:788-799.

5. Oikawa T, Sasaki T, Nakamura M, Shimamura M, Tanahashi N, Omura S, Tanaka K. The proteasome is involved in angiogenesis. Biochem Biophys Res Commun. 1998; 246:243-248. [PubMed: 9600100]

6. Beg AA, Baltimore D. An essential role for NF-kappaB in preventing TNF-alpha-induced cell death. Science. 1996; 274:782-784. [PubMed: 8864118]

7. Zetter BR. Adhesion molecules in tumor metastasis. Semin Cancer Biol. 1993; 4:215-218. [PubMed: 8400143]

8. Read MA, Neish AS, Luscinskas FW, Palombella VJ, Maniatis T, Collins TC. The proteasome pathway is required for cytokine-induced endothelial-leukocyte adhesion molecule expression. Immunity. 1995; 2:493-506. [PubMed: 7538441]

9. Hideshima T, Richardson P, Chauhan D, Palombella VJ, Elliott PJ, Adams J, Anderson KC. The proteasome inhibitor PS-341 inhibits growth, induces apoptosis, and overcomes drug resistance in human multiple myeloma cells. Cancer Res. 2001; 61:3071-3076. [PubMed: 11306489]

10. Hideshima T, Mitsiades C, Akiyama M, Hayashi T, Chauhan D, Richardson P, Schlossman R, Podar K, Munshi NC, Mitsiades N, et al. Molecular mechanisms mediating antimyeloma activity of proteasome inhibitor PS-341. Blood. 2003; 101:1530-1534. [PubMed: 12393500]

11. Richardson PG, Sonneveld P, Schuster M, Irwin D, Stadtmauer E, Facon T, Harousseau JL, BenYehuda D, Lonial S, Goldschmidt H, et al. Extended follow-up of a phase 3 trial in relapsed multiple myeloma: final time-to-event results of the APEX trial. Blood. 2007; 110:3557-3560. [PubMed: 17690257]

12. San Miguel JF, Schlag R, Khuageva NK, Dimopoulos MA, Shpilberg O, Kropff M, Spicka I, Petrucci MT, Palumbo A, Samoilova OS, et al. Bortezomib plus melphalan and prednisone for initial treatment of multiple myeloma. N Engl J Med. 2008; 359:906-917. [PubMed: 18753647]

13. Goy A, Bernstein SH, Kahl BS, Djulbegovic B, Robertson MJ, de Vos S, Epner E, Krishnan A, Leonard JP, Lonial S, et al. Bortezomib in patients with relapsed or refractory mantle cell lymphoma: updated time-to-event analyses of the multicenter phase 2 PINNACLE study. Ann Oncol. 2009; 20:520-525. [PubMed: 19074748]

14. San-Miguel JF, Richardson PG, Sonneveld P, Schuster MW, Irwin D, Stadtmauer EA, Facon T, Harousseau JL, Ben-Yehuda D, Lonial S, et al. Efficacy and safety of bortezomib in patients with renal impairment: results from the APEX phase 3 study. Leukemia. 2008; 22:842-849. [PubMed: 18200040]

15. Dimopoulos MA, Richardson P, Schlag R, Khuageva NK, Shpilberg O, Kastritis E, Kropff MH, Petrucci MT, Delforge M, Alexeeva JA, et al. A Prospective, Randomized, Phase III Study of Bortezomib, Melphalan, Prednisone and Thalidomide (VMPT) Versus Bortezomib, Melphalan and Prednisone (VMP) in Elderly Newly Diagnosed Myeloma Patients. Blood. 2008; 112:1727a.

16. Therasse P, Arbuck SG, Eisenhauer EA, Wanders J, Kaplan RS, Rubinstein L, Verweij J, Van Glabbeke M, van Oosterom AT, Christian MC, et al. New guidelines to evaluate the response to treatment in solid tumors. European Organization for Research and Treatment of Cancer, National Cancer Institute of the United States, National Cancer Institute of Canada. J Natl Cancer Inst. 2000; 92:205-216. [PubMed: 10655437]

17. Cheson BD, Bennett JM, Grever M, Kay N, Keating MJ, O'Brien S, Rai KR. National Cancer Institute-sponsored Working Group guidelines for chronic lymphocytic leukemia: revised guidelines for diagnosis and treatment. Blood. 1996; 87:4990-4997. [PubMed: 8652811]

18. Cheson BD, Horning SJ, Coiffier B, Shipp MA, Fisher RI, Connors JM, Lister TA, Vose J, GrilloLopez A, Hagenbeek A, et al. Report of an international workshop to standardize response criteria for non-Hodgkin's lymphomas. NCI Sponsored International Working Group. J Clin Oncol. 1999; 17:1244-1253. [PubMed: 10561185] 
19. Blade J, Samson D, Reece D, Apperley J, Bjorkstrand B, Gahrton G, Gertz M, Giralt S, Jagannath $\mathrm{S}$, Vesole D. Criteria for evaluating disease response and progression in patients with multiple myeloma treated by high-dose therapy and haemopoietic stem cell transplantation. Myeloma Subcommittee of the EBMT. European Group for Blood and Marrow Transplant. Br J Haematol. 1998; 102:1115-1123. [PubMed: 9753033]

20. Prepared by a Committee of the Chronic Leukemia--Myeloma Task Force, National Cancer Institute. Proposed guidelines for protocol studies. II. Plasma cell myeloma. Cancer Chemother Rep. 1968; 3(1):17-39.

21. Lightcap ES, McCormack TA, Pien CS, Chau V, Adams J, Elliott PJ. Proteasome inhibition measurements: clinical application. Clin Chem. 2000; 46:673-683. [PubMed: 10794750]

22. Stewart AK, Sullivan D, Lonial S, Mohrbacher AF, Chatta G, Shustik C, Burris H, Karol M, Zannikos P, Reece DE. Pharmacokinetic (PK) and Pharmacodynamics (PD) Study of Two Doses of Bortezomib (Btz) in Patients with Relapsed Multiple Myeloma (MM). Blood. 2006; 108:1008a.

23. Melamed, J. Repeat-Dose Pharmacokinetics and Pharmacodynamics of Bortezomib in Patients with Relapsed Multiple Myeloma. Cambridge, MA: Millennium Pharmaceuticals, Inc.; 2005. Report No. M34103-058 CSR

24. Chanan-Khan AA, Richardson P, Lonial S, Siegel D, Jagannath S, Mehta J, Doran J, Singhal S. Safety and Efficacy of Bortezomib in Multiple Myeloma Patients with Renal Failure Requiring Dialysis. Blood. 2005; 106:716a.

25. Ludwig H, Adam Z, Hajek R, Greil R, Keil F, Zojer N, Thaler J, Gisslinger H, Lang A. Bortezomib-Doxorubicin-Dexamethasone (BDD) for Reversal of Acute Light Chain Induced Renal Failure (ARF) in Multiple Myeloma (MM). Results from a Phase II Study. Blood. 2008; 112 Abstr 3682.

26. Pekol T, Daniels JS, Labutti J, Parsons I, Nix D, Baronas E, Hsieh F, Gan LS, Miwa G. Human metabolism of the proteasome inhibitor bortezomib: identification of circulating metabolites. Drug Metab Dispos. 2005; 33:771-777. [PubMed: 15764713]

27. Leger F, Seronie-Vivien S, Makdessi J, Lochon I, Delord JP, Sarda C, Canal P, Chatelut E. Impact of the biochemical assay for serum creatinine measurement on the individual carboplatin dosing: a prospective study. Eur J Cancer. 2002; 38:52-56. [PubMed: 11750839] 
A

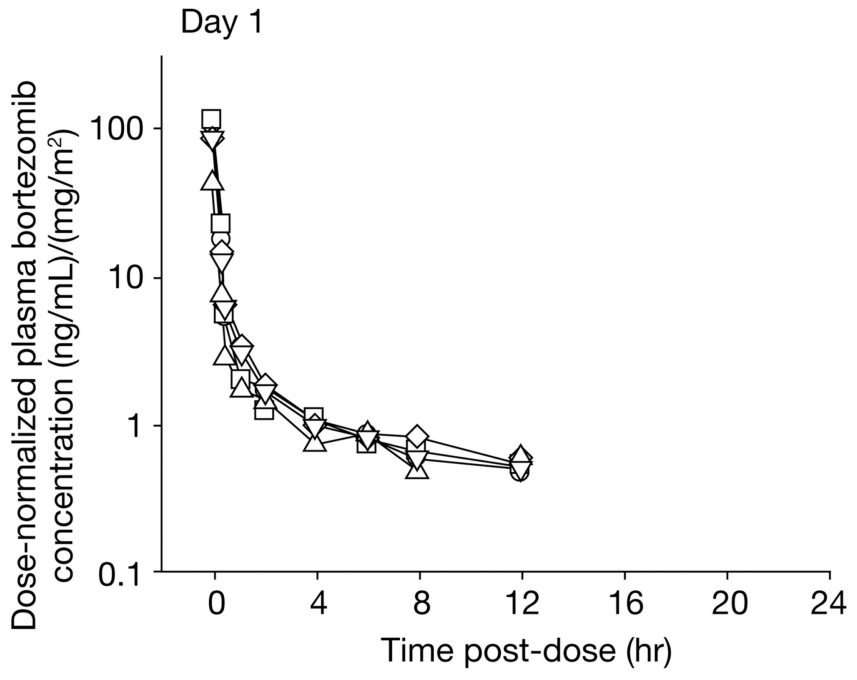

B

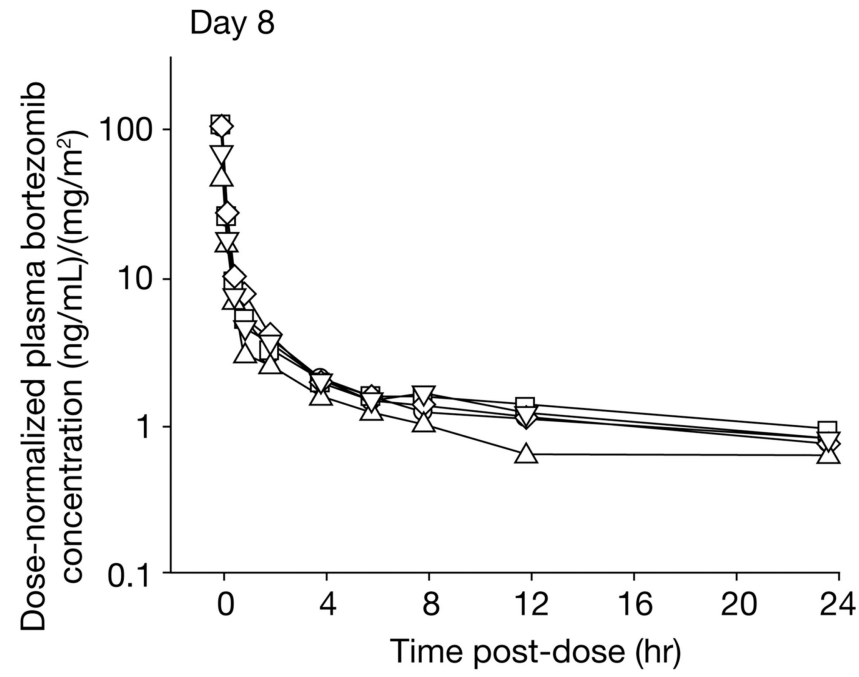

-๑ Normal $\square$ Mild impairment $\diamond$ Moderate impairment $\quad \smile$ Severe impairment $\quad \nabla$ Dialysis

Figure 1.

Median dose-normalized plasma concentration-time profiles of bortezomib on days 1 and 8 by renal function category. 
A

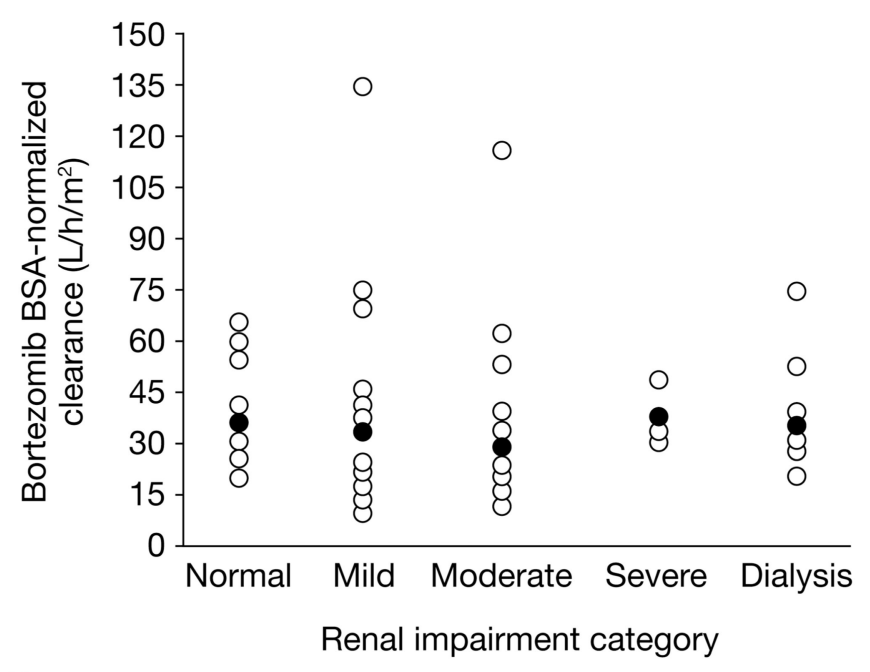

B

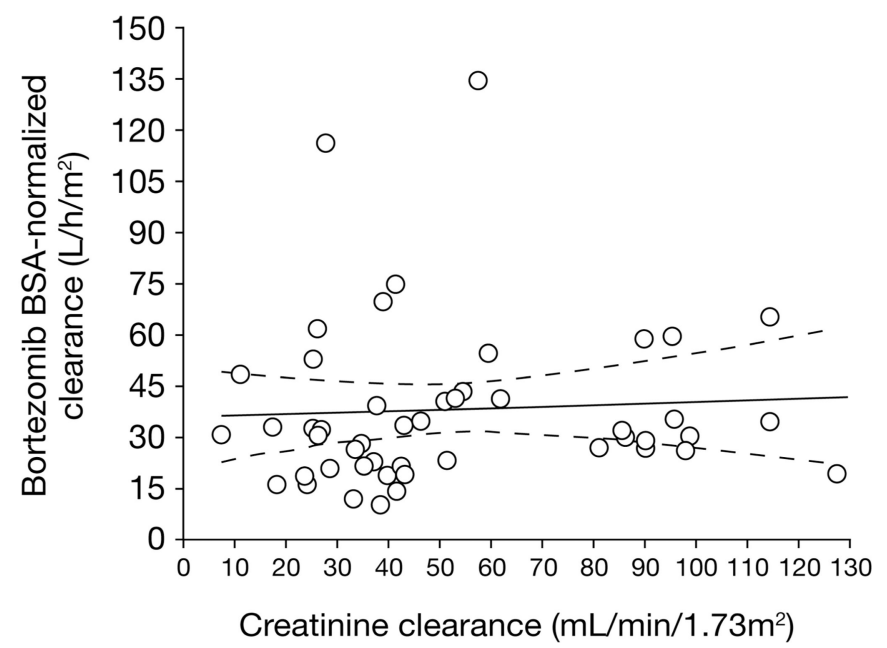

C

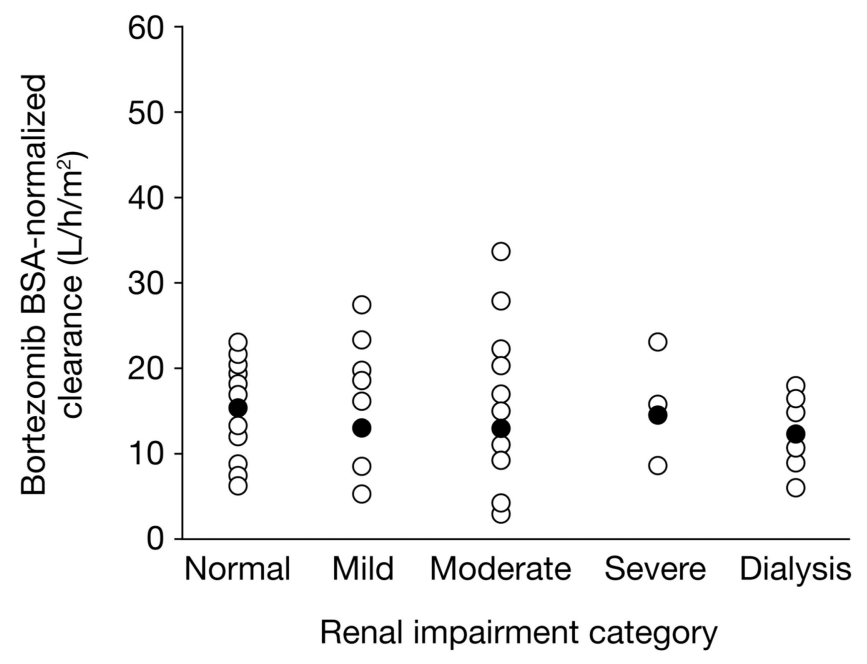

D

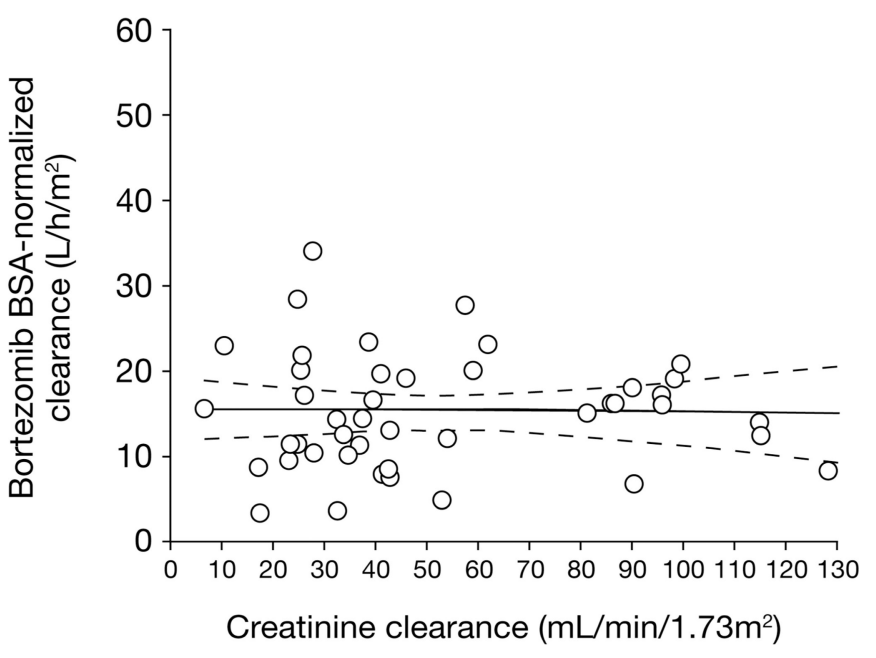

Figure 2.

Scatter plots of individual BSA-normalized bortezomib clearance on day 1 (panels A and B) or day 8 (panels $\mathrm{C}$ and $\mathrm{D}$ ) by renal function category (panels A and C) or BSA-normalized creatinine clearance as a continuous variable (panels B and D). In panels A and C, the open circles are individual patient data and the closed circles are geometric means within each renal function group. In panels B and D, the solid and dashed lines are model-estimated regression lines and associated $95 \%$ confidence limits, respectively. 


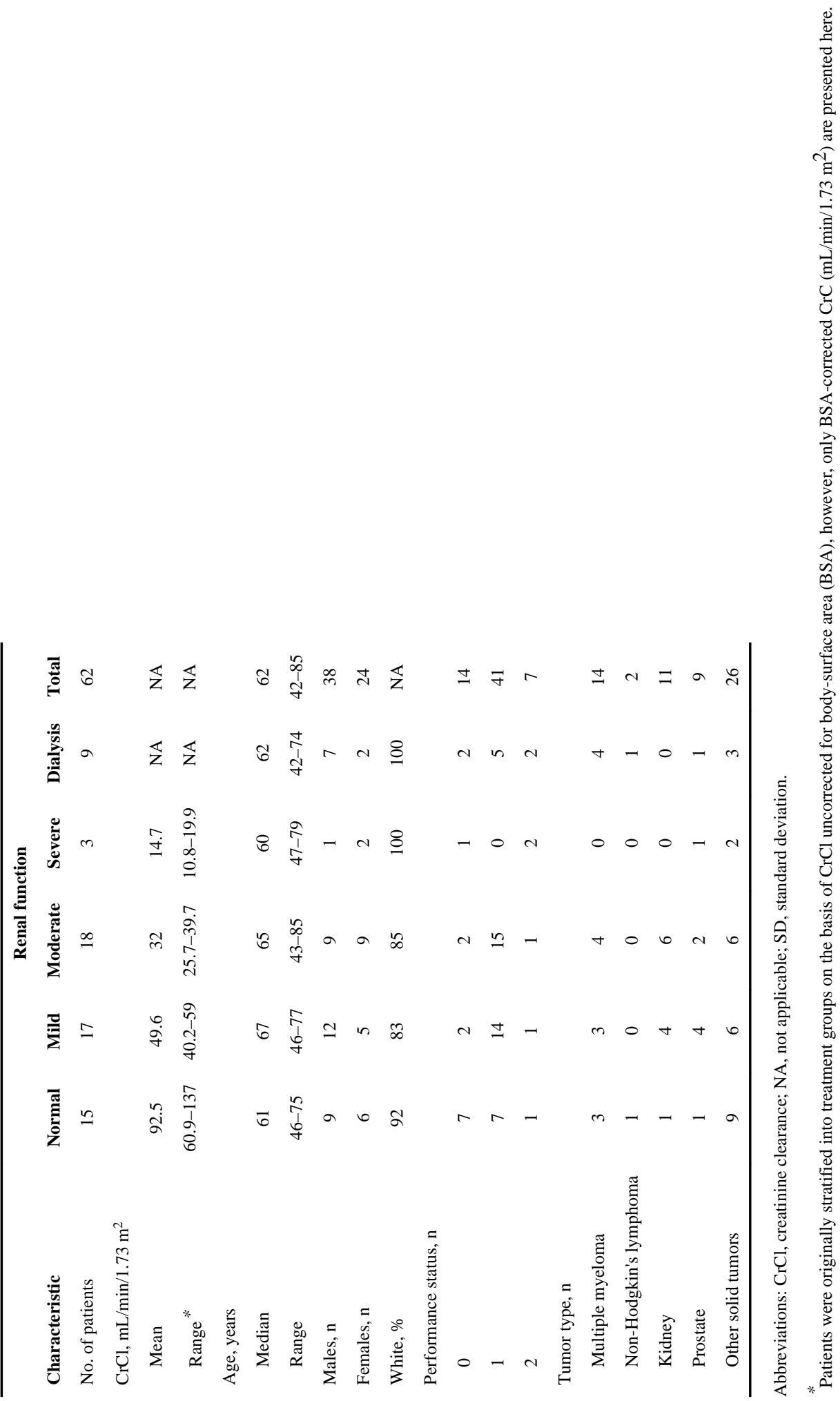




\begin{tabular}{|c|c|c|c|c|c|c|c|c|c|c|c|c|c|c|c|c|c|c|c|}
\hline 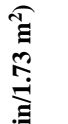 & 解 & & $\stackrel{\nabla}{\vec{\imath}}$ & $\overleftrightarrow{z}$ & & $\begin{array}{l}\infty \\
\infty \\
\infty\end{array}$ & $\stackrel{0}{0}$ & & İ & $\stackrel{\infty}{\dot{m}}$ & $\stackrel{\infty}{0}$ & & $\stackrel{F}{F}$ & $\overleftrightarrow{z}$ & $\overleftrightarrow{z}$ & & $\overleftrightarrow{z}$ & $\mathbb{z}$ & $\overleftrightarrow{z}$ \\
\hline 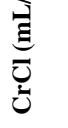 & 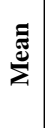 & & ڤે & $\vec{a}$ & & $\underset{\infty}{\infty}$ & 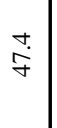 & & $\begin{array}{l}\overrightarrow{0} \\
\stackrel{i}{\sim}\end{array}$ & : & $\frac{a}{m}$ & & $\stackrel{\check{ \pm}}{ \pm}$ & $\overleftrightarrow{z}$ & $\overleftrightarrow{z}$ & & $\overleftrightarrow{z}$ & $\overleftrightarrow{z}$ & $\overleftrightarrow{z}$ \\
\hline$\frac{\tilde{\omega}}{0}$ & 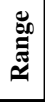 & & $\hat{\imath}$ & $\overleftrightarrow{z}$ & & $\underset{\sim}{+}$ & 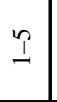 & & $\stackrel{\infty}{\sim}$ & $\stackrel{\hat{\imath}}{m}$ & $\stackrel{I}{I}$ & & 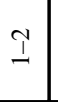 & $\mathbb{z}$ & $\mathbb{Z}$ & & $\overleftrightarrow{z}$ & $\underset{\sim}{+}$ & $\underset{\sim}{\stackrel{I}{d}}$ \\
\hline $\begin{array}{l}0 \\
\stackrel{0}{E}\end{array}$ & $\sum_{\Sigma}^{\Xi}$ & & $r$ & - & & $m$ & $N$ & & $n$ & 으 & $\nabla$ & & - & $\overleftrightarrow{z}$ & $\overleftrightarrow{Z}$ & & $N$ & $m$ & $\stackrel{\sim}{\dot{f}}$ \\
\hline ڤે & 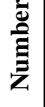 & & 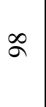 & - & & $\infty$ & లె & & तิ & లి & ले & & $\nabla$ & 0 & 0 & & 0 & 0 & $\curvearrowright$ \\
\hline 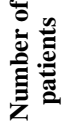 & & $\simeq$ & \pm & - & $\Xi$ & $m$ & $\Xi$ & 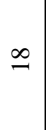 & $\nabla$ & $m$ & $=$ & $m$ & $m$ & 0 & 0 & $a$ & $m$ & $N$ & $\nabla$ \\
\hline & & 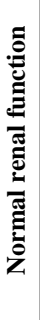 & 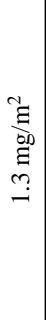 & 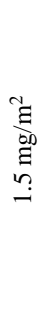 & 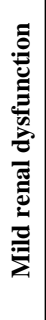 & $\begin{array}{c}\stackrel{N}{Z} \\
\stackrel{0}{\Xi} \\
-\end{array}$ & 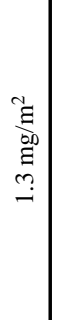 & 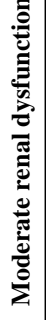 & $\begin{array}{c}\stackrel{N}{\Xi} \\
\text { bD } \\
\Xi \\
\stackrel{5}{0}\end{array}$ & $\begin{array}{l}\text { Eี } \\
\text { है } \\
\Xi \\
-\end{array}$ & 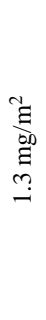 & 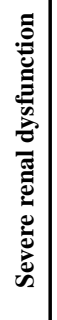 & 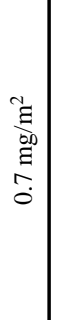 & $\begin{array}{l}\stackrel{N}{E} \\
\stackrel{0}{00} \\
\Xi \\
-\end{array}$ & 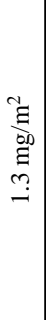 & 旾 & $\begin{array}{c}\stackrel{N}{E} \\
\vdots \\
\Xi \\
\vdots \\
0\end{array}$ & $\begin{array}{c}\stackrel{N}{\Xi} \\
\text { D. } \\
\Xi \\
-\end{array}$ & $\begin{array}{l}\stackrel{N}{E} \\
\stackrel{\Delta}{\Xi} \\
\stackrel{\Xi}{-}\end{array}$ \\
\hline
\end{tabular}




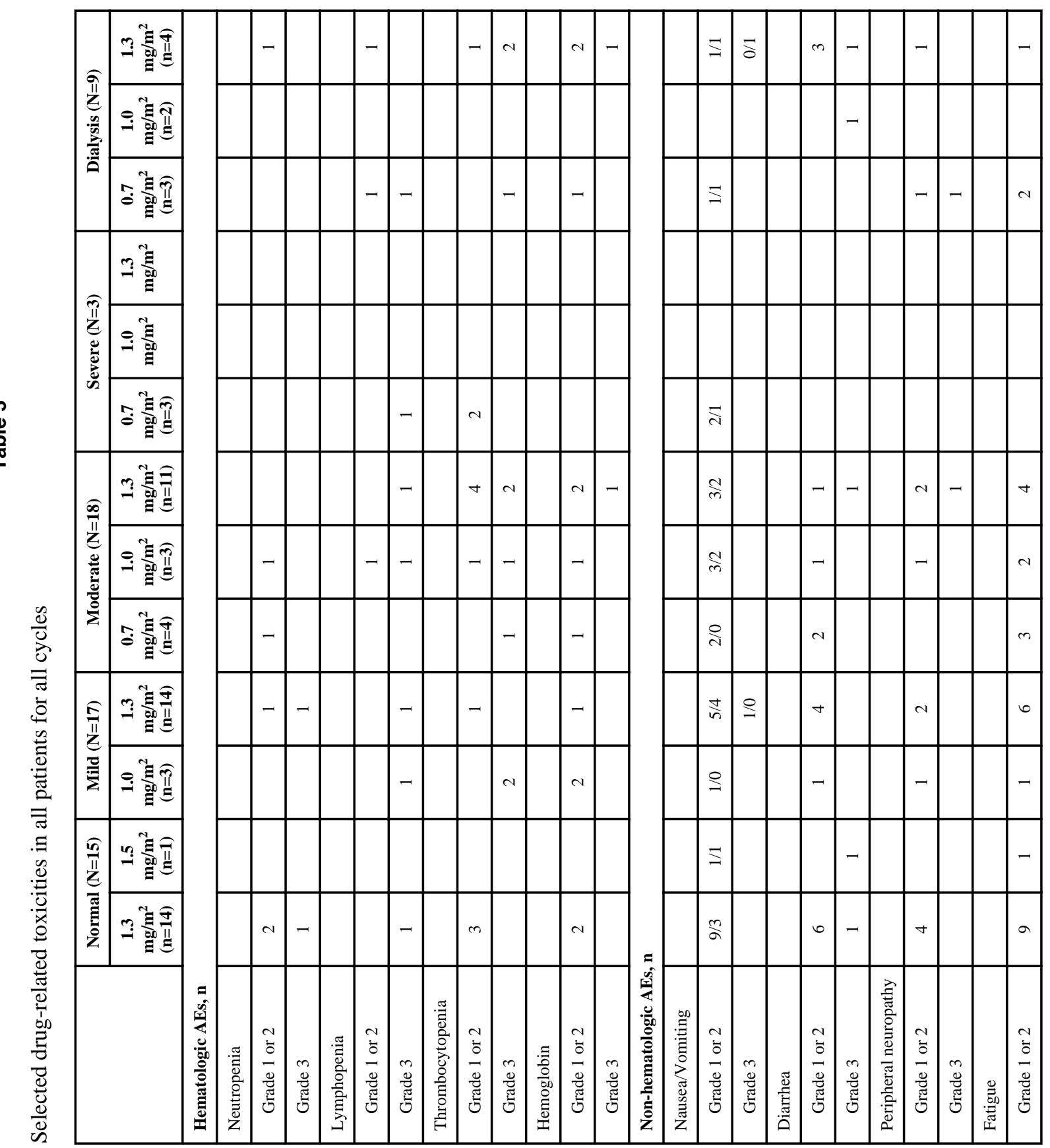




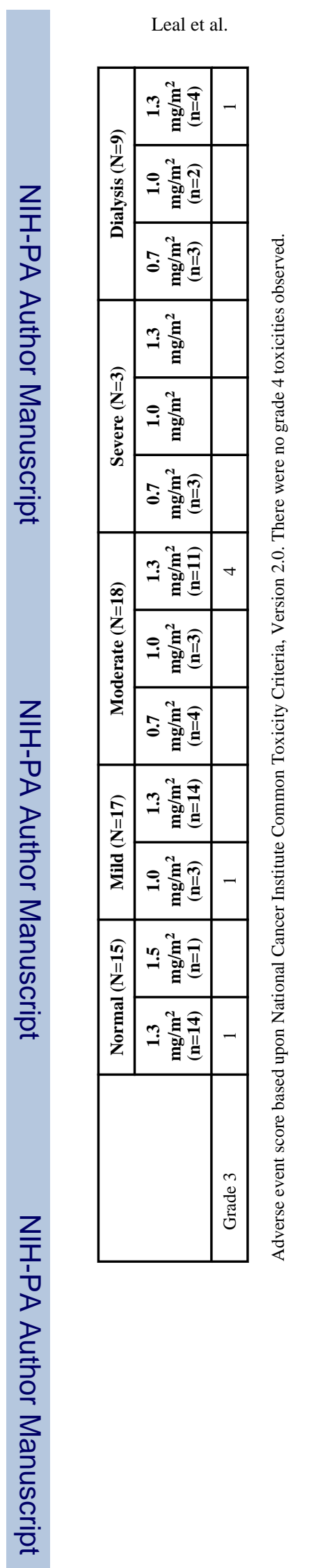


